\title{
The Current State of Outdoor Learning in a U.K Secondary Setting: Exploring the Benefits, Drawbacks and Recommendations
}

\section{Ryan Thomas Williams ${ }^{1 *}$, Carla Daniella Scott ${ }^{2}$}

${ }^{1}$ School of Social Sciences, Humanities and Law, Teesside University, Middlesbrough, TS1 3BX, United Kingdom

${ }^{2}$ MA in Education, Sheffield Hallam University, Sheffield, S1 1WB, United Kingdom

${ }^{*}$ Corresponding Contact:

Email: ryan.williams@tees.ac.uk

Manuscript Received: 27 August 2019 - Revised: 17 Oct 2019 - $\quad$ Accepted: 20 Nov 2019

\begin{abstract}
The purpose of the present study was to understand why secondary teachers are not using outdoor learning (OL) in their pedagogical practice. Through the lens of social constructivism (Vygotsky, 1986; Trowler, 2008) the research aims were to 1) examine the current benefits and drawbacks of OL, 2) distinguish factors that influence teachers' perceptions of OL, and 3) determine, using teachers' perceptions, if OL has a greater impact on child development than indoor learning (OL). Seven teachers were selected using purposeful sampling from a U.K secondary school. An adapted version of Fagerstam's (2014) teachers' perceptions questionnaire was administered to gather responses across social aspects, supporting environment, teacher-student relations, and teacher collaboration. Results from thematic analysis generated risk assessment, weather, time, flexibility, behaviour, relationships, and definition as key themes. Furthermore, results showed that there is educational potential for OL, however this does not have to be in the form of a Forest School Experience. Some teachers were in disagreement on whether the change in pupils' behaviour is perceived as positive or negative, although there were differences in year groups. The author proposes that there are educational, personal development and fluidity factors that need to be addressed by policy makers and school leaders to encourage teachers to use the outdoor facilities more. Additionally, school leaders could use Kennedy's (2005) award bearing model as professional development to standardise the quality of OL taking place in schools. Future research must examine the links between OL and cognitive development as much of the research in the area is through the lens of social constructivism.
\end{abstract}

Keywords: Outdoor Learning, Secondary School, Pupils' Behavior

This article is is licensed under a Creative Commons Attribution-NonCommercial 4.0 International License. 


\section{INTRODUCTION}

With growing pressure on educationalists across all phases of schooling, teachers are now looking at more creative ways to provide opportunities for young people to reflect, think and support the learning process. Outdoor learning (OL) has a long history of providing special places for individuals to teach (Beard \& Wilson, 2006). For the purpose of this research, OL can be defined as structured learning activities that occur in the outdoor environment within the school grounds (Rickinson et al., 2004; Fägerstam, 2014). The benefits of OL have been aptly discussed in the literature and include: linking abstract thinking; physical activity; taking risks; and enjoyment (Fiskum \& Jacobsen, 2012; Mygind, 2007; Maynard, Waters, \& Clement, 2013). When pupils enjoy their rich sensory environment, motivation towards learning can be enhanced (Waite, 2011).

OL has recently undergone a transformation from a classroom that is outdoors, into a vast recreational playground of unpredictable elements (Turner, 2005). Contrastingly, Indoor Learning (IL) has remained a four walled building whereby children have the opportunity to enhance their knowledge and skills through conventional ways of teaching and learning (Dhanapal \& Lim, 2013). Some of the benefits of IL include, behaviour management, structure and routine. Legett and Newman (2017) argued that there is an absence of these benefits in OL environments, with the role of a teacher switching to a more 'supervisory' responsibility when working outdoors. However, it is important to recognise that previous applications of OL, especially in the United Kingdom (U.K.), merely put focus on it as a utility location, rather than an integral part of the learning process. Successful outdoor provision requires as much thought, preparation and planning as provision indoors (White, 2007).

Visions of learning outside the secondary classroom has been a part of the mainstream UK educational context since 1950 (Hunt, 1989, cited in Rubens, 1997, p.1). It wasn't until the obesity epidemic in 2006, that the U.K and the Labour administration introduced the Learning outside the Classroom Manifesto (Labour Party Manifesto 2005), aimed at facilitating a young person's experience beyond the classroom in addition to promoting an active lifestyle. More recently, the education secretary, Damian Hinds shared his desire to move the curriculum away from a regime of exams and rigid curricula, into a skills based curriculum where children learn through experience (Vaughan, 2018).

Modern day classrooms allow for multiple pedagogical approaches to be applied (Greenaway, 1999 as cited in Beard \& Wilson, 2006), yet there seems to be an invisibility of good pedagogy in centralised education (see Lusted, 1986; Ladwig et al., 2007; Giroux \& Shannon, 2013). This is illuminated in OL, and previous studies have referenced that teachers feel they lack an understanding of OL as a teaching strategy to apply it effectively. In a social context, the National Education Charity (NEC), Learning Through Landscapes (LTL) have mentioned that only $8 \%$ of school age children in England get out of their classrooms into green spaces (Project Dirt 2018). Thus, it is active practitioners, i.e. teachers who can provide a sound understanding of the phenomenon, over policy makers.

\section{LITERATURE REVIEW}

\section{Defining Outdoor Learning}

OL presents opportunities for increased participation by both, the learner and educator (Joyce, 2012; Learning through Landscapes, 2006; Project Dirt, 2018). The last few decades has seen OL become highly visible in the public domain, such as, appearing in magazines, 
on television, on the internet, and now being firmly embedded in the early year's curriculum (DfES, 2007 as cited in Joyce, 2012). This emphasis on a child's relationship with the natural environment in the context of formal education, takes focus of the development of self-constructs and team work (Waite et al., 2016; Norodahl \& Johanesson, 2013; Dyment et al., 2017). An increase in participation means the definition of OL is forever evolving, for example in the 1980s OL was simply defined as 'exploring in a safe environment outdoors' (Ellsworth, 1989). Modern day researchers and educators now view OL as a rich and varied environment that supports children's learning and development (EYFS framework, 2008; DfCSF, 2008). Teachers are now moving away from going outdoors and children playing with loose materials into more established outdoor provision that offers quality learning (Rickinson et al., 2004). The importance of OL cannot be underestimated, it is not as simple as going outdoors for tasks that can be completed in a classroom, but about providing authentic and contextualise opportunities that extend classroom based learning (James \& Williams, 2017). Additionally, there are significant differences between OL and child play as highlighted by Grow to School (2019, p.1):

'Forest Schools sessions are child led and do not link to the curriculum. Grow sessions are shown to increase pupil motivation and inspiration and connect learning to real life examples.'

Despite a contrast in definitions, a reoccurring theme throughout the last few decades is that there is an invisibility in good pedagogical practice in the outdoor teaching and learning environment. There is evidence that when outdoor experiences are regarded as having inherent educational value and equivalence as classroom learning, OL can support curriculum delivery effectively (Macquarrie, 2018; Prince, 2018).

\section{History of Outdoor Learning}

Compulsory education came into statute in 1870, but it wasn't until 1911 when educator, Margaret McMillan introduced nursery school gardens for children under 5, was a link made between a healthy body and a healthy mind. McMillan also came to the conclusion that the school environment had to be conducive to learning. After World War 1 (WW1), buildings were being purposefully erected for nursery learning (under $5 \mathrm{~s}$ ) and for the first time, included, paths, logs, barrels, seats, tables, ropes, swings and playhouses, as well as a plethora of natural materials such as trees, ponds, bark and twigs (Bilton, 2010). The new learning environments, often referred to as an 'oasis' by McMillan and 'divorced from reality' by theorist Owen (1928) were intended for children to 'play, construct, and follow their interests without interruption from adults' (Bilton, 2010). McMillan (1930, p.120) writes:

'The nursery garden is the essential matter. Not the lessons, or the pictures or the talk. The lessons and talk are about things seen and done in the garden, just as the best of all the paintings in picture galleries are shadows of the originals now available to children of the open air.'

Learning through play in an interesting environment was seen as a way to help young people develop (McMillan, 1930; Isaacs, 1954). The pioneers of this period also saw the need for trained outdoor specialists (de Lissa, 1939). Another World War (WWII) saw women free up to do more work and moving into education, either as a nursery teacher or secondary teacher was a popular choice. The four to six day training course which was required at the time, covered numeracy, literacy, behaviour management and outdoor learning (Blackstone, 1971). A statutory element of OL was widened by the 1944 Education 
Act, ensuring that the provision for primary, secondary and further education included 'adequate facilities for recreation and social and physical training' (Education Act 1944, cited in Cook 1999). Local Education Authorities (LEAs) took responsibility of offering a similar public school experience for working class pupils by maintaining playing fields, outdoor play centres amongst other facilities (Cook, 1999; Freeman, 2011). A further Education Reform Act in 1988 introduced the National Curriculum (NC) and Key Stages (KS), making Physical Education (P.E) a compulsory element for learners 5-16. During this period, outdoor education was growing at a rapid pace, and charities such as the Duke of Edinburgh Award (DofE) was formed. By 1975, over 1 million children had taken part in a DofE scheme to transform their lives through physical activities and life skills (DofE, 2019). With loose safety acts in place, outdoor education in schools flourished, with teachers' high in confidence taking children outdoors to explore near rivers, ponds and marshes (Simmons, 2010). However, The Lyme Bay Canoeing Tragedy (1993), where four children died whilst on a school trip, prompted tighter regulation around risk assessments and child safety. Despite assurances from LOtC, teachers still view risk assessments as a restrictive barrier to going outdoors (Waite, 2010), with many claiming the risk averse culture of today impinges upon their freedom to offer experiential learning.

In 2006, the U.K was facing an obesity epidemic, as activity levels were dropping in young people due to parents' concerns around safety, and a development in digital technologies. The Labour administration (1997-2010) recognised outdoor education would benefit a child's wellbeing and implemented new initiatives to 'providing young people with a wide range of experiences outside the classroom' (DfES, 2006, p.1). Since then, the Council for Learning Outside the Classroom (CLOC) whose remit covers 'ten areas that include arts and creativity, sacred space, school grounds, natural environment and adventure education' had its funding cut (Passey et al., 2010). With no policy measures and a variation in financial and structural support between schools for outdoor learning, some are now exploring digital technologies as a priority (LOtC, 2010). Interestingly, examples of Forest Schools still firmly believe that outdoor learning should remain a priority in terms of funding (HoC, 2010). In 2012, in an attempt to push outdoor provision, there was deregulation in health and safety around adventurous activities but the impact of this is still unclear.

Right now, outdoor learning is underpinned by character building of the 'disadvantaged child', largely because it is a low cost method to inspire children. As current policy makers search for new creative solutions to economic problems, they may recognise the potential of outdoor learning to foster creative thinking, practical hands-on active learning and the co-construction of successful learning experiences outside of school (Passey et al., 2012).

\section{Outdoor Learning or Learning Outdoor?}

The benefits of outdoor learning is widely publicised, and educational policy has been set out in previous manifestos to encourage learning outside the classroom (Learning Outside the Classroom Manifesto, Department for Education Skills (DfES) 2006). Although, Rickinson et al. (2004) argues that there is a lack of consensus about what 'outdoor education' comprises. Rea (2008) debates that learning outdoors is or should be the same as what is encountered inside, providing a continuous and seamless learning experience for the child (DfES, 2007). However, other scholars have suggested the sheer scale of being outdoors completely changes the sort of learning experiences children have, and part of the motivation from children to work outdoors is the departure of familiar classroom context (see Edgington, 2002; Broderick \& Pearce; Rea, 2008). Additionally, Forest schools have reported how free play and child initiated 
exploration of the natural environment engages children far greater than adult led activities (Waite \& Davis, 2007). Therefore, there are indications that learning is affected by the outdoor context and this means a change to the pedagogy employed by practitioners (Pascal \& Bertram, 1997; Williams, 2018; Rickinson et al., 2011). Waite (2011) found the successful OL pedagogy embraced freedom, fun, authenticity, autonomy and physicality and involved child-led activities. For example, a foundation stage teacher describes a successful lesson plan, despite a lack of resources at the school:

'Sustainability and spirituality are both part of the school curriculum. We can begin to develop the children's understanding at an early age by teaching them to love their planet, experience things deeply, relate to the outside world and have real experiences. We can create a sense of awe and wonder by developing their understanding of the outside world, through interest and excitement in their environment.' (Waite, 2011, p.67)

Therefore, pedagogy should embrace values listed above and contexts which afford personal engagement and enjoyment for both child and practitioner (Waite, 2011). In terms of future development, Moore and Wong (1997) found evidence for lasting academic and behavior effects on those children involved in the development of diverse school grounds.

\section{MetHodology}

\section{Data Collection}

In total, seven participants were recruited to complete an adapted version of Fagerstam's (2014) questionnaire $(n=7)$ ( 2 male and 5 female). Participants had teaching experience ranging from 2-12 years and all held QTS. The teachers ranged from classes EYFS-Y6 (4-11 years). Prior to the project, teachers were familiar with the outdoor facilities in the school from teaching and learning outdoors. In Fagerstam's (2014) study a total of 12 participants were used across the different departments in school. The rationale for subject selection was governed by logistical and practical issues, such as covering classes to complete the questionnaire. Although, NQT's and SLT's were omitted from the selection process. Purposeful sampling was used to collect data and teachers had to meet the following criteria: hold QTS, teaching for over two years, used the outdoor learning facilities at the school. One rationale for purposeful sampling is its effectiveness in studying a certain cultural domain with knowledgeable experts (Tongsco, 2007). In addition to knowledge and experience, Bernard (2002) argues that it is important for participants to be willing to communicate experiences, options, and to articulate in an expressive manner. Contrastingly, random sampling is used to ensure the generalizability of findings and minimizing any potential bias (Spradley, 1979). Participants were chosen after initial conversation with the head teacher and there was consideration to those who had other responsibilities and therefore could not take part. Additionally, face to face contact was made with the selected participants and the study was fully explained to all those taking part and informed consent obtained.

\section{Materials}

Fagerstam (2014) teachers' experience questionnaire was developed to explore how teachers have explored the educational potential of OL in a high school settings. The structure of the questionnaire split into various themes supported thematic analysis. An adapted version of Fagerstam's (2014) teachers' experience questionnaire was administered to measure responses across social aspects, supporting environment, teacher-student relations, and teacher collaboration, allowing a detailed look into teachers' 
perceptions of OL. In total, 8 questions were used across these sections. Fagerstam (2014) recommended 30-60 minutes to complete the questionnaire. Each participant had up to 60 minutes to complete the questionnaire. The questionnaire was designed using SurveyMaker, and participants completed this online.

\section{Data Analysis}

Thematic analysis was conducted to analyze the dataset (Boyatzis, 1998; Braun \& Clarke, 2006; 2013). In thematic analysis, the researcher seeks to identify, analyze and report patterns within the empirical material (Fagerstam, 2014). Szklarski (2009) argues that this could be seen as from 'within interpretation', where the researcher interprets direct expressions, rather than creating categories. Data was analyzed using Braun and Clarke's (2006) six phases.

\section{FINDINGS}

\section{The Themes}

Table 1: Summary of themes

\begin{tabular}{ll}
\hline Theme & Sub- themes \\
\hline Risk assessment & $\begin{array}{l}\text { Risk averse culture } \\
\text { Time }\end{array}$ \\
\hline Weather & Behaviour \\
& Enjoyment \\
\hline Workload/time & Extra planning \\
& Timetable demands \\
& Flexibility \\
\hline Flexibility & Assessment \\
& Resources \\
& Curriculum \\
\hline Behaviour & Confidence \\
& Weather \\
& Anxiety \\
& Distractions \\
\hline Relationships & Student-teacher \\
& Behaviour \\
\hline Definition & Evidence \\
& Assessment \\
\hline
\end{tabular}

\section{Social Aspects}

Table 2: Summary of perceptions concerning social aspects of outdoor learning

\begin{tabular}{lll}
\hline \multicolumn{2}{l}{ Social aspects } & \\
\hline Question & Theme & Sub-themes \\
\hline $\begin{array}{l}\text { What are the top three challenges of teaching lessons } \\
\text { outdoors? }\end{array}$ & Time & $\begin{array}{l}\text { Flexibility } \\
\text { Timetabling } \\
\end{array}$ \\
\cline { 2 - 3 } & & Planning \\
\hline
\end{tabular}




\begin{tabular}{|c|c|c|}
\hline & Management & $\begin{array}{l}\text { Resources } \\
\text { TA } \\
\text { Weather }\end{array}$ \\
\hline \multirow[t]{3}{*}{$\begin{array}{l}\text { How does the teacher-student relationship change when } \\
\text { working outdoors and how does this impact the structure of } \\
\text { your lesson? }\end{array}$} & Behaviour & $\begin{array}{l}\text { Confidence } \\
\text { Improves } \\
\text { Resilience } \\
\text { Engagement }\end{array}$ \\
\hline & Structure & $\begin{array}{l}\text { Enjoyment } \\
\text { Routine } \\
\text { Exploring }\end{array}$ \\
\hline & Risk & $\begin{array}{l}\text { More time } \\
\text { Risk averse }\end{array}$ \\
\hline
\end{tabular}

\section{Supporting Environment}

Table 3: Summary of perceptions concerning supporting environment of outdoor learning

\begin{tabular}{|c|c|c|}
\hline \multicolumn{3}{|c|}{ Supporting environment } \\
\hline Question & Theme & Sub-themes \\
\hline \multirow[t]{3}{*}{$\begin{array}{l}\text { How does student participation change when working } \\
\text { outdoors? }\end{array}$} & Mood & $\begin{array}{l}\text { Engagement } \\
\text { Enthusiastic } \\
\text { Less pressure } \\
\text { Fun } \\
\text { Effective }\end{array}$ \\
\hline & Distraction & $\begin{array}{l}\text { Focus } \\
\text { Concentration } \\
\text { Lack of structure }\end{array}$ \\
\hline & Relationship & $\begin{array}{l}\text { Team-work } \\
\text { Group-work } \\
\text { Structure }\end{array}$ \\
\hline \multirow[t]{2}{*}{$\begin{array}{l}\text { How does the organisation of groups change when } \\
\text { working outdoors, and how does this impact on } \\
\text { collaborative learning experiences? }\end{array}$} & Mixed ability & $\begin{array}{l}\text { Assessment } \\
\text { Challenge } \\
\text { New friendships }\end{array}$ \\
\hline & Behaviour & $\begin{array}{l}\text { Structure } \\
\text { Anxiety }\end{array}$ \\
\hline \multirow[t]{4}{*}{$\begin{array}{l}\text { If you had a magic wand, what would you want to help } \\
\text { you teach lessons outdoors more often? }\end{array}$} & Resources & $\begin{array}{l}\text { Purposeful } \\
\text { Productive } \\
\text { Seats } \\
\text { TA } \\
\text { Kit } \\
\text { Inside E outside } \\
\text { Toilets }\end{array}$ \\
\hline & Time & $\begin{array}{l}\text { Flexibility } \\
\text { Set up }\end{array}$ \\
\hline & Collaboration & Share ideas \\
\hline & Evidence & Assessment \\
\hline
\end{tabular}




\section{Teacher-Student Relations}

Table 4: Summary of perceptions concerning teacher-student relations and outdoor learning

\section{Teacher-student relations}

\begin{tabular}{|c|c|c|}
\hline Question & Theme & Sub-themes \\
\hline \multirow{4}{*}{$\begin{array}{l}\text { How does the behaviour of pupils change } \\
\text { when learning outdoors, and how does } \\
\text { this impact your behaviour management? }\end{array}$} & Vulnerable Groups & $\begin{array}{l}\text { Struggle } \\
\text { Routine }\end{array}$ \\
\hline & Boundaries & $\begin{array}{l}\text { Relationships } \\
\text { Expectations } \\
\text { BFL } \\
\text { Maintaining }\end{array}$ \\
\hline & Better & $\begin{array}{l}\text { Confidence } \\
\text { Enjoyment } \\
\text { Engaged } \\
\text { Self-esteem }\end{array}$ \\
\hline & Distractions & $\begin{array}{l}\text { Weather } \\
\text { Playtime } \\
\text { Struggle with change }\end{array}$ \\
\hline \multirow[t]{3}{*}{$\begin{array}{l}\text { How do you perceive the mood of the } \\
\text { lesson when working outdoors by a) the } \\
\text { student and b) the teacher? }\end{array}$} & Enjoyment & $\begin{array}{l}\text { Change of scenery } \\
\text { Good feedback } \\
\text { Weather } \\
\text { Fun } \\
\text { Students }\end{array}$ \\
\hline & Stressful & $\begin{array}{l}\text { No challenge } \\
\text { Trying to evidence } \\
\text { Time }\end{array}$ \\
\hline & Relaxed & $\begin{array}{l}\text { BFL } \\
\text { Challenge }\end{array}$ \\
\hline
\end{tabular}

\section{Teacher Collaboration}

Table 5: Summary of perceptions concerning teacher collaboration and outdoor learning

\section{Teacher collaboration}

\section{Question}

\begin{tabular}{ll} 
Theme & Sub-themes \\
Confidence & $\begin{array}{l}\text { Impacts collaboration } \\
\text { Links to curriculum }\end{array}$ \\
Creative & $\begin{array}{l}\text { Useful } \\
\text { Sharing } \\
\end{array}$ \\
& $\begin{array}{l}\text { Rarely happens } \\
\text { Strategies for BFL }\end{array}$ \\
\hline Regular & $\begin{array}{l}\text { As much as indoor } \\
\text { Year collaboration } \\
\end{array}$ \\
& Outdoor specialist
\end{tabular}




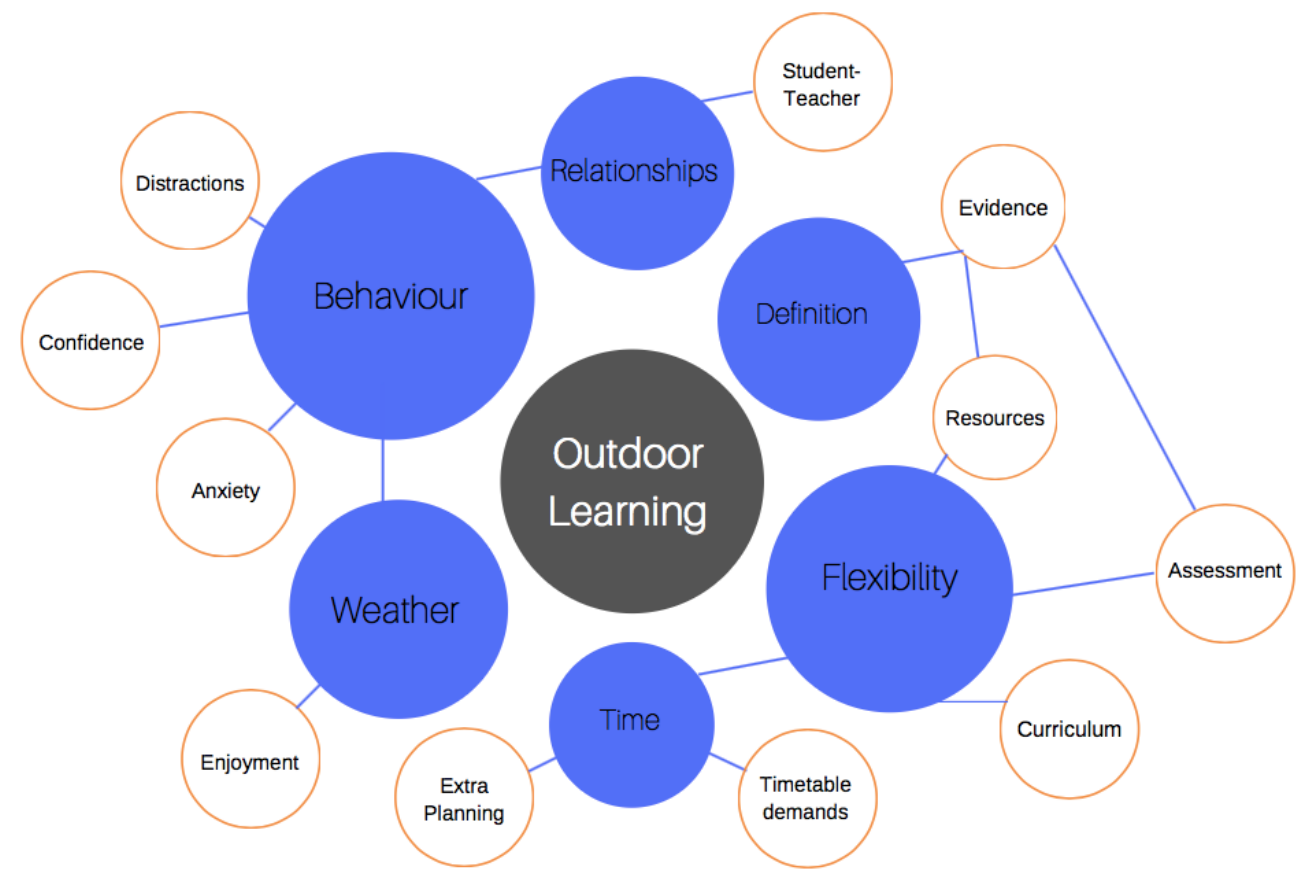

Figure 1: Thematic analysis map

\section{Discussion}

The purpose of the present study was to understand why teachers are not using OL in their pedagogical practice. Much of the literature in this area adopts a social culturalist view to teachers working outdoors (Trowler, 2008; Culatta, 2019; Dayang, 2013), with research showing that few teachers are taking part in structured lessons outside the traditional indoor classroom. More specifically, when teachers are taking students outdoors the drivers are field trips, camping trips, excursions and environmental education.

Firstly, the results from this study suggest that there is educational potential for outdoor provision in the primary context by simply going outdoors, and this supports previous researchers' claims across early years and secondary phases (Fagerstam, 2014). These results demonstrate that it is not essential for students to travel to a forest or outdoor centre to facilitate participatory learning (see Tovey, 2007; Forest School, 2009). Previous research has suggested that there is a need to follow Nordic countries in the Forest School experience (FSE). In the present study, teachers report similar 'exploratory' and 'child-led' experiences when going outside in the playground. Thematic analysis yielded key themes from eight questions that relate to the author's research aims and objectives (Figure 1). The author proposes that there are educational, personal development, and fluidity factors that impact teachers' use of the outdoor facilities in OL. It is these factors that ought to be addressed by policy makers and school leaders.

Teachers feel that there is an agenda to teach more outdoor lessons, and the literature shows that in recent years, there has been a push in the media, alongside political manifestos using OL in dialogue around child obesity. This would suggest that OL must 
be active and take curricula practices from physical education. Yet, in the school used for this study, there has been investment in a tepee and training on taking subjects such as mathematics from the classroom into the tent. Teachers are receiving inconsistent messages about OL, and this tension has left teachers unsure over the definition of OL, and more specifically how this can determine the structure of a lesson.

This confusion is illuminated in the literature, for example, there are scholars that have argued learning outdoors should be the same as what is encountered inside (as in Rea, 2008) and this is similar to the approach the school has taken. Contrastingly, there are scholars that argue the vast difference of being outdoors compared to the indoor context suggests different pedagogical strategies should be deployed. This is exemplified in the Labour Party Manifesto (2005). However, there is consensus that working outdoors should be fun, exploratory and child-led (Pascal \& Bertram, 1997; Rickinson et al., 2011). Therefore, once policy makers and leaders in school agree (through consistent messages) that OL is fun, should embrace freedom, is authentic and consists of child-led activities, then it is the expert practitioners, i.e. teachers who can be left to their own devices to create a plethora of lessons and resources. In other words, the fundamentals of OL (fun, exploratory, child-led) hint that there is not a 'one shoe fits all' approach to panning. Interestingly, defining OL was not a theme that came in Fagerstam's (2014) study that used a sample of 12 secondary teachers, compared with 7 secondary teachers in the present study.

Teachers acknowledge that there are teaching and learning differences between IL and OL. For example, responses showed that there were behavioural, engagement and mood variations. Interestingly, teachers had mixed perceptions whether these changes were positive ('more fun', 'less stressful'), or negative ('more distractions', 'more stressful'). These differences go beyond personal preferences and into a social cultural approach (Trowler, 2008) to learning. As the culture differs in KS1 to KS2, teachers' views and beliefs also differ. More specifically, teachers in KS1 where OL was more prominent had the necessary skills to adapt to the changes in child behaviour and engagement. Contrastingly, teachers in KS2 where OL is more unknown did not have the skills to adapt to these changes. Christie et al. (2012) predicted that the success of OL is dependent on teachers' prior experience.

From an educator's perspective, there is widespread agreement that effective CPD is an important component of educational success (Atencio, Jess \& Dewar, 2012; DarlingHammond et al., 2009). Thus, highlighting the importance of addressing CPD issues in relation to OL. There is an active debate in the literature around whether it should be the organisation (school), or individual (teacher) who takes responsibility of CPD (Weller, 2009). When thought is put into CPD, it can appear complex and this can result in educators not partaking in CPD, meaning it is the school's responsibility to take to provide effective CPD. Kennedy's (2005) award bearing model of CPD is viewed as a mark of quality assurance and could be used to ensure standardization of experiences. More specifically, researchers have argued that teachers must complete a number of necessary hours of OL per year (Henderson, 2002; Kennedy, 2005). The experience gained from this will change the views and beliefs of teachers, as well as the culture of the class.

Results showed that flexibility and time were two of the most used words by the respondents. Teachers are in agreement that the curriculum is not flexible enough to allow for more OL, especially when it comes to evidencing and/or producing assessments. However, there are methods of assessment as indicated in Moncrieff (2012), such as 
photographs, although this method does have limitations. Teachers are also worried about resources at school not being flexible enough for the outdoor environment. Furthermore, teachers reported that a lack of time was a reason why they don't go outdoors more often. These fluidity issues are well publicized in the literature (Moncrieff, 2012; Waite, 2011) and the digital agenda faces the same challenges. Similar to the digital agenda, these factors are influenced by political and economic factor that can only be addresses by policy makers in Westminster. The Conservative Party makes reference to an 'active education' and a 'skills' based curriculum in their latest manifesto (Conservative Party Manifesto, 2017). The indication that OL is important now needs to be fraught with questions on the 'how'. When OL is made a priority, and when teachers have adequate time to plan for flexible curricula, the outdoor environment will be used more frequently.

\section{Future RESEARCH}

Previous studies have argued that student motivation may be an obstacle to OL (Bentsen et al., 2010; Han \& Foskett, 2007), however this is still contentious in the literature with many arguing that OL increases motivation (Mygind, 2007). Additionally, there is no research concerning secondary pupils' attitudes and emotions towards school-based outdoor learning and its educational potential (Jarvis, 2006), specifically in relation to motivation and enjoyment. Therefore, future research should investigate motivation and enjoyment levels from pupils' perspectives.

Moreover, new research argues that there are links between emotions and cognition (Immordino-Yang, 2011), and the idea that positive feelings could be associated with problem solving and memory skills in OL is of interest and should be examined further.

Finally, this research presents three factors that need to be addressed by policy makers and school leaders, educational, personal development, and fluidity. These factors may link into the challenges that are faced in secondary settings, yet, there is no research that discusses these in the wider education context.

\section{REFERENCES}

Beard, C. M., \& Wilson, J. P. (2006). Experiential learning: A best practice handbook for educators and trainers. Kogan Page Publishers.

Bertram, T., Pascal, C. (2002) 'Early Years Education: An International Perspective, Centre for Research in Early Childhood, Birmingham' Educational Research,

Bilton, H. (2010) Outdoor Learning in the Early Years: Management and Innovation. Routledge Ltd. Available at: https://www.dawsonera.com:443/abstract/9780203860137.

Blackstone, T. (1971) A Fair Start The Provision of Pre-School Education. London. Allen Lane. The Penguin Press.

Boyatzis, R. (1998). Transforming qualitative information: Thematic analysis and code development. Thousand Oaks, CA: Sage.

Braun, V \& Clarke, V. (2013) 'Successful Qualitative Research: A Practical Guide for Beginners Virginia Braun, Victoria Clarke - Google Books', p. 382.

Braun, V., \& Clarke, V. (2006). Using thematic analysis in psychology. Qualitative Research in Psychology,

British Council (2019). Guided discovery. Retrieved from: https://www.teachingenglish.org.uk/article/guided-discovery 
Williams and Scott: The Current State of Dutdar Learning in a U.K Secandary Setting: Exploring the Benefits, Drawbacks \& Recommendations (IDS-122)

British Educational Research Association (BERA) (2004) Ethical guidelines for educational research. Available at: https://www.bera.ac.uk/researchers-resources/publications/ethical-guidelinesfor-educational-research-2018 (Accessed April 2019).

Christie, B. (2012). The impact of outdoor learning experiences on attitudes to sustainability: A review of literature. Prepared for Field Studies Council. Edinburgh: University of Edinburgh.

Cook, B., Heseltine, P.(1999) Assessing Risk on Children's Playgrounds (2 ${ }^{\text {nd }}$ edn). Birmingham: RoSPA.

Culatta, R. (2019) Learning Theories, Available at: https://wwww.instructionaldesign.org/theories/

Dayang, I. (2015) 'A New Pathway towards Retirement Preparation: Integration of Holistic Lif', European Journal of Social Sciences Education and Research, 2(4), pp. 154-160

DCSF (2008) Staying Safe Action Plan. Cross-government Strategy for Improving Children and Young People's Safety. London: DCSF Publications.

De Lissa, Lillian. (1939). Life in the nursery school. London: Longmans, Green

Department for Education and Employment (DfEE). 1998. The national literacy strategy.

DfES (2006). Learning outside the Classroom Manifesto. Nottingham, DfES Publications.

Dhanapal, S., \& Lim, C. C. Y. (2013, December). A comparative study of the impacts and students' perceptions of indoor and outdoor learning in the science classroom. In Asia-Pacific Forum on Science Learning \& Teaching (Vol. 14, No. 2).

Dyment, J. (2008). Green School Grounds as Sites for Outdoor Learning: Barriers and Opportunities. International Research in Geographical and Environmental Education, 14 (1), 28-45.

Ellsworth, E. (1989) Teaching Positions: Difference, Pedagogy, and the Power of Address. New York: Teachers College Press.

Fägerstam, E. (2014). High school teachers' experience of the educational potential of outdoor teaching and learning. Journal of Adventure Education \& Outdoor Learning, 14(1), 56-81.

Fiskum, T., \& Jacobsen, K. (2012). Relation between the School Environment and the Children's Behaviour. The Open Education Journal, 5(1).

Giroux, H.A. and Shannon, P., 2013. Education and cultural studies: Toward a performative practice. Routledge.

Gov.UK. 'England's largest outdoor learning project reveals children more motivated to learn when outdoors'. Press release published 14 July 2016. www.gov.uk/government/news/englandslargest-outdoor-learning-project-reveals-children-more-motivayed-tolearn-when-outdoors Accessed 20 July 2016.

Grow to School (2019) About Outdoor Learning, Available at: https://wwww.growtoschool.co.uk (Accessed: April 2019).

Guba, E. G., \& Lincoln, Y. S. (1994). Competing paradigms in qualitative research. In N. K. Denzin \& Y. S. Lincoln (Eds.), Handbook of qualitative research (pp. 105-117). Thousand Oaks, CA: Sage

House of Commons, Children, Schools and Families Committee (2010) Transforming Education outside the Classroom, http://www.publications.parliament.uk/pa/cm200910/cmselect/cmchilsch/418/41802.htm (accessed 16.12.11).

Isaacs, S. (1954). The Educational Value of Nursery School: London: The nursery School Association

James, J. K., \& Williams, T. (2017). School-Based Experiential Outdoor Education: A Neglected Necessity. Journal of Experiential Education, 40(1), 58-71.

Joyce, Rosaleen. Outdoor Learning: Past And Present, McGraw-Hill Education, 2012. ProQuest Ebook Central, https://ebookcentral.proquest.com/lib/tees/detail.action?docID=863804.

Labour Party (2005) Labour Party Manifesto, Labour Party. 
Ladwig, J., Smith, M., Gore. J., Amosa, W., Griffiths, T. (2007) 'Quality of pedagogy and student achievement: multi-level replication of authentic pedagogy', Australian Association for Research in Education pp.1-15.

Learning Through Landscapes (2006) Learning without boundaries, Available at: https://wwww.ltl.org.uk/projects/outdoor-classroom-day/\#about (Accessed: April 2019).

Little, J.W. (2003) Inside teacher community: representations of classroom practice. Teachers College Record 105: 913-945.

Lusted, D. (1986) 'Why Pedagogy?', Screen 27(5) pp.2-16.

MacQuarrie, S. (2018). Everyday teaching and outdoor learning: developing an integrated approach to support school-based provision. Education 3-13, 46(3), 345-361.

Maynard, T., Waters, J., \& Clement, J. (2013). Moving outdoors: further explorations of 'childinitiated' learning in the outdoor environment. Education 3-13, 41(3), 282-299.

Moncrieff, D. (2012) 'Interactive Learning and Assessment for Learning (AfL) in the Outdoor Classroom', NAFSO, 1(), pp. 20-23

Moore, R.C., and H.H. Wong. 1997. Natural learning: The life of an environmental schoolyard. Creating environments for rediscovering nature's way of teaching. Berkeley, CA: MIG Communications.

Mygind, E. (2007). A comparison between children's physical activity levels at school and learning in an outdoor environment. Journal of Adventure Education \& Outdoor Learning, 7(2), 161-176.

Norodahl, K., \& Johannesson, I. A. (2016). "Let's go outside": Icelandic teachers' views of using the outdoors. Education 3-13, 44(4), 391-406.

OFSTED (2018). School inspection handbook. Retrieved from: https:/ /assets.publishing.service.gov.uk/government/uploads/system/uploads/attachment_d ata/file/730127/School_inspection_handbook_section_5_270718.pdf

Ofsted (2018). Early years foundation stage statutory framework (EYFS). London: Department for Education.

Outdoor Classroom Day (2018). Not Enough Children Learning and Playing Outside. Retrieved from: https://outdoorclassroomday.org.uk/2018/05/17/not-enough-children-learning-andplaying-outside/

Owen, G. (1928) Nursery School Education. London. Methuen.

Pascal, C., and T. Bertram. 1997. Effective early learning: Case studies in improvement. London: Hodder and Stoughton.

Passey , R., Rea, T., Williams, A., Wood, C., (2012) Outdoor learning policy development in England and Wales School of Education, Plymouth University, UK.

Passey, R., and S. Waite. 2010. 'Excellence and enjoyment' continuing professional development materials in England: Both a bonus and onus for schools. Journal of In- Service Education 34, no. 3: 311-25.

Plymouth University (2016) 'Transforming Outdoor Learning in Schools'.

Prince, Heather (2018) Changes in outdoor learning in primary schools in England, 1995 and 2017: lessons for good practice. Journal of Adventure Education and Outdoor Learning

Project Dirt (2018) The impact of outdoor learning and playtime at school - and beyond, Available at: https://outdoorclassroomday.com/wp-content/uploads/2018/05/FINAL-Project-Dirt-Survey-OutdoorPlay-and-Learning-at-School-2018-15.05.18.pdf (Accessed: March 2019).

Rea, T. \& Waite, S. (2008) Taken over? Schooling and Outdoor Education In: C. Martin and Mark Wagstaff (Eds.) Controversial Issues in Adventure Programming, Human Kinetics: Champaign, IL. 
Williams and Scott: The Current State of Dutdoor Learning in a U.K Secondary Setting: Exploring the Benefits, Drawbacks g Recommendations (I0马-I22)

Rickinson, M. et al (2004). A review of research on outdoor learning. National Foundation for Educational Research, King's College London. Field studies council, ISBN, 1(85153), 893.

Rubens, D. (1997). Outdoor education, adventure and learning: A fusion. Edinburgh: University of Edinburgh.

Simmons, D. (2010). Using Natural Settings for Environmental Education: Perceived Benefits and Barriers. The Journal of Environmental Education, 29(3), 23-32.

Tongsco, M. (2007) 'Purposive Sampling as a Tool for Informant Selection', Ethnobotany Research and Applications, (1), pp. 147-157.

Tovey, H. (2007) Playing Outdoors. Spaces and Place, Risk and Challenges. Maidenhead: Open University Press.

Trowler, P., 2008. Cultures and change in higher education: Theories and practices. Macmillan International Higher Education.

Vaughan, R. (2018). Exclusive: Damian Hinds tells schools to 'get kids climbing trees' to build character.

Vygotsky, L. S. (1978) Mind in Society. Development of higher Psychological Processess. Cambridge MA: Harvard University Press.

Vygotsky, L. S. (1986). Thought and language-Revised edition.

Waite, S. (2011) Teaching and learning outside the classroom: personal values, alternative pedagogies and standards, Education 3-13, 39:1, 65-82, DOI: 10.1080/03004270903206141

Waite, S. (2011). Teaching and learning outside the classroom: Personal values, alternative pedagogies and standards. Education 3-13: International Journal of Primary, Elementary and Early Years Education, 31(1), 65-82.

Waite, S. (2011). Teaching and learning outside the classroom: Personal values, alternative pedagogies and standards. Education 3-13, 39(1), 65-82.

Williams, R. T. (2018). Confidence Interventions: Do They Work?. Asian Journal of Humanity, Art and Literature, 5(2), 123-134. https://doi.org/10.18034/ajhal.v5i2.536

$--0--$ 